\title{
An Android based Information System for Cargo Delivery
}

\author{
John Rarui Ngugi \\ Faculty of Information Technology \\ Strathmore University \\ Nairobi, Kenya
}

\author{
Allan Odhiambo Omondi \\ Doctoral Fellow, Faculty of Information Technology \\ Strathmore University \\ Nairobi, Kenya
}

\begin{abstract}
This research investigates the problems related to the logistics industry specifically the trucking industry. It implements the solutions in form of an Android mobile application. The transport industry is one of the biggest industries in Kenya. With Kenya holding the ports via which landlocked countries such as Uganda import goods, the development of the standard gauge railway offers stiff competition to the trucking sector. In addition to this, the move by the internet service providers to extend their coverage and the dropping prices of smartphones increased the number of people with android phones and internet access in Kenya. To enable the solution offered by the research to have a positive impact and high adoption rate, the project implemented its solution in the form of an android application. The project took an object-oriented approach in its analysis and design taking the rapid application development methodology to ensure minimal errors and continuous improvement.
\end{abstract}

\section{Keywords}

Trucking, transportation, mobile application, finger travel distance.

\section{INTRODUCTION}

The trucking sector is one of the most important sectors globally. Trucking facilitates trade and other socio-economic activities both directly and indirectly affect the GDP of a country. Freight transport is also a major contributor to a country's economic growth ensuring imports and exports are delivered to their destinations. In addition, the trucking sector is a major contributor to employment opportunities. According to Bureau of Transportation Statistics, by 2002 there were 4.4 million workers in the for-hire transport industry in the United States with $60 \%$ of them being in the freight transportation sector.

Over time, the trucking sector has been evolving with popularization of new practices such as the use of just-in-time procurement [6]. Just-in-time systems are systems advocating for timely procurement and production practices. These practices began in the 1970's and have been attributed to success of companies such as Toyota. Recently, with the boom of ecommerce, the concept of globalization and free trade, just-in-time procurement and delivery systems have been increasingly adopted. Worldwide retail ecommerce sales are set to reach $\$ 4.479$ trillion by the year 2021 from $\$ 2.290$ trillion in 2017 [1]. The amount of cargo delivery is also expected to increase as a result of this.

In addition to these, there are various problems facing the trucking sector. Taking an example of East Africa, high transportation costs and cargo theft are some of the challenges facing this sector [9]. For example, in Kenya, shipping a $20 \mathrm{ft}$ container from the port in Mombasa to Nairobi takes 42 hours and costs 90,000 Kenyan shillings by road in comparison to railway which takes 18 hours and costs 50,000 Kenyan shillings [5].

To solve these problems and take advantage of the market provided by the new practices stated, trucking companies should leverage on popular technologies such as the smartphone to offer consumer centered services in the competitive field of trucking. According to Statista, the number of smartphone usage around the world is expected to rise from 1.57 billion in 2014 to 2.87 billion in 2020 [8]. Considering these statistics along with the popularization of technologies such as GPS, online and mobile payment solutions and data analytics, cargo delivery companies should employ these technologies to create a consumer centered and cost-effective strategy in their competition while reducing cargo theft problems through tracking and monitoring. In addition, the use of these technologies will help generate insightful data applicable in improving of customer services effectively.

The rest of the paper is organized as follows: Section II clearly defines the problem and provides a review of related research, and smartphone technologies. It also goes ahead to review existing transport solutions in Kenya. Section III explains the system development methodology that was used to develop the solution and Section IV provides the results of the tests conducted on the developed system. Section V then provides the conclusion.

\section{LITERATURE REVIEW}

\subsection{Current problem}

Taking a case study of Kenya, with the current system where a producer searches for his own means of transport in addition to high prices on trucks (Kenya Transporters Association, 2017), there is slow conversion of the products to profit. The producer takes time searching for trucks. Take a case of a large-scale farmer. He usually bands together with other farmers to transport their goods to the market together requiring a minimum of 10 trucks. To procure the trucks manually, he starts the current processes which are searching, vetting the truck found, agreeing on the price and procurement. These are processes which he does for each truck. In some cases, negotiations can break down during agreement over price which returns him back to the first part of the process. During the process, it is important to note that he has not yet transported any of his produce to the market yet.

In addition, with the current system it is difficult to track your cargo especially if you have hired more than one vehicle. With this comes the problem of cargo theft [9]. Cargo theft is a contributor to loss of profits. This problem is seen in various sectors from oil transport by road to transport of produce from 
farms and goods from industries. Without a way of tracking the actions of the driver, including stops made, it turns out to be difficult to explain partial loss of cargo transported. In other cases, total loss of commodities is experienced where a driver makes off with the cargo. In both cases, however the losses have to be covered by both the producer who misses market profits and the truck owner who has to pay up for the cargo lost.

Without standard pricing set for transport of cargo from one place to another, it is left up to the driver to decide his charges. As such there is a gap between what the cargo owner is willing and prepared to pay and what he should pay. Currently cargo haulage takes $30 \%$ of the value of goods transported in Kenya (Kenya Transporters Association, 2017). This reduces the popularity of road transport in preference to other means of transport like rail where possible. With the construction of the standard gauge railway in Kenya majority of haulage along the route will be taken from the road sector to the trains.

\subsection{Smartphone usage statistics}

According to Consumer Barometer [4], 43\% of Kenyans owned smartphones as of January 2018 with $59 \%$ spending more time on smartphones than computers or tablets as shown in figure 1. In addition the continuous global rise in smartphone ownership to 2.87 billion people by 2020 as shown in figure 2 .

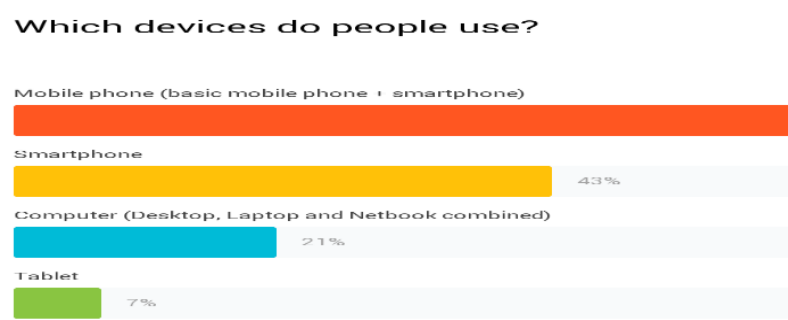

Figure 1 Percentage usage of devices in Kenya [4]

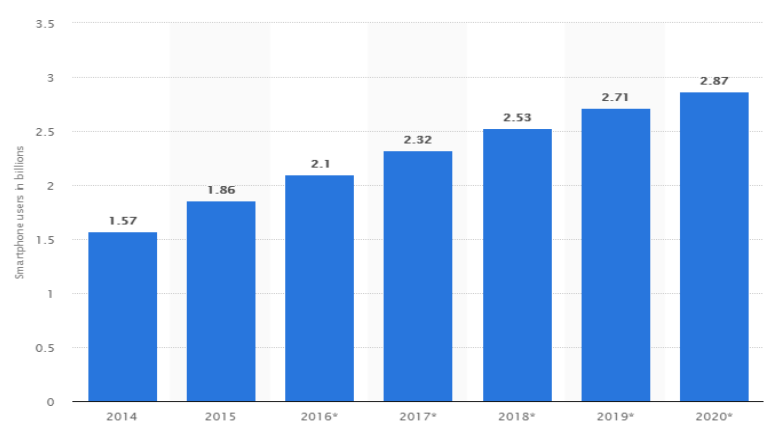

Figure 2 Growth of smartphone users worldwide per year [8]

\subsection{Modern smartphone-based technologies}

\subsubsection{Geofencing}

This is placing a boundary to monitor a given geographical region. Alerts are created upon entry and exit from the region [2]. This is used to view the objects within a predefined radius. In a cargo delivery system, geofencing can be used to determine the vehicles around the consumer at a given moment. This controls the selection of trucks to ensure timely expected times of arrival (ETA) to the consumer thus maintaining consumer satisfaction.

\subsubsection{GPS}

Ground Positioning System (GPS) is a technology that gives the location of an object. The inclusion of this technology in mobile phones allows it to be accessible to a large number of people. Coupling this technology with maps gives the user a graphical geographical position. Application of this technology will allow for monitoring operations in a cargo delivery system. [2].

\subsubsection{Distance matrix}

Distance matrix is the calculation of distance and travel times to determine the best route for travel. Currently, mobile development companies such as Google are offering an application programming interface (API) that allows for this function in smartphone applications [3].

\subsubsection{Geofire}

Geofire is a service offered by Google that combines GPS with a real-time database. Continuous updating the GPS coordinates of an object to the database coupled with constant retrieval in real-time allows for a cost effective method of monitoring [12].

\subsection{Existing transport solutions in Kenya}

\subsubsection{Senga}

Senga.co is a website where cargo owners contact the company to request for transport from the company.[7]

\subsubsection{How Senga works}

The cargo owner gets the contacts from the website and contacts them with information on the cargo and the distance to be covered. They tell him the price and if he accepts then they order the required trucks for him. They keep track of the trucks on his behalf and the driver gets paid after delivery of all goods is confirmed. This process is seen in figure 3 below.

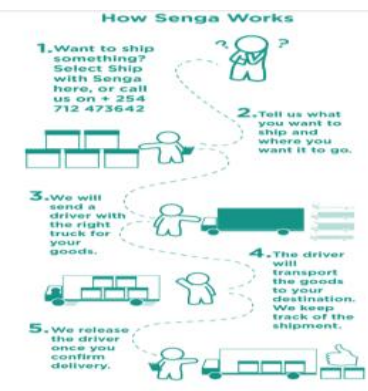

Figure 3: Screenshot of Senga [7]

\subsubsection{UBER}

Uber is a taxi booking system that connects drivers to potential clients. It is a mobile app running on both android and apple phones. [11] 


\subsubsection{How it works}

\section{HOW UBER WORKS}

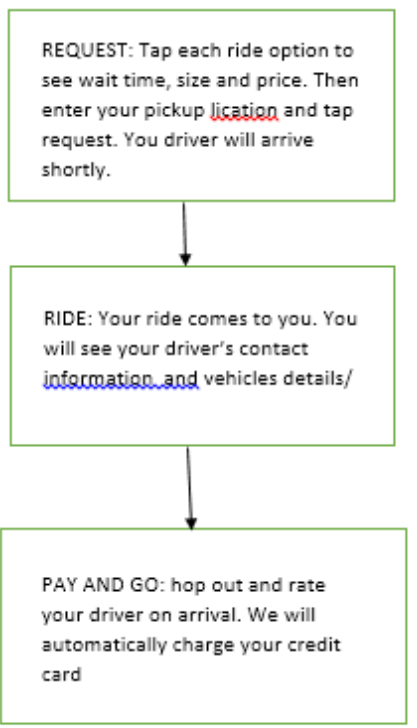

Figure 4: a figure depicting how uber functions [11]

Using Uber, a rider requests a taxi from the app. The rider inputs the locations and Uber outputs the price at which stage the rider has the option of ordering a taxi. The driver then accepts the request [11]. The mobile interface is shown in figure 5. Figure 6 shows the request page in the app.

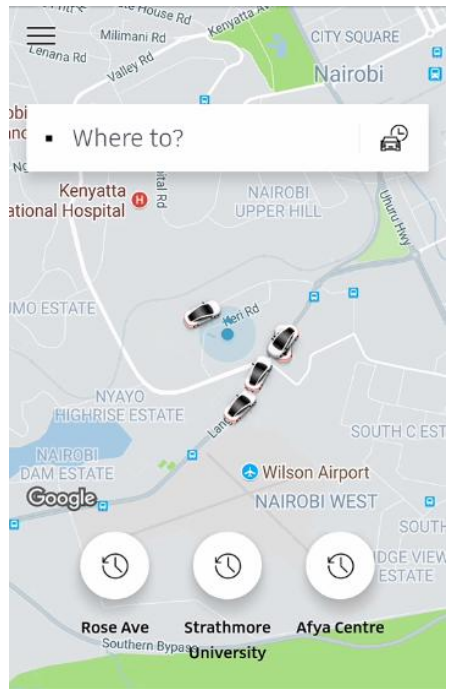

Fig 5: screenshot of Uber interface

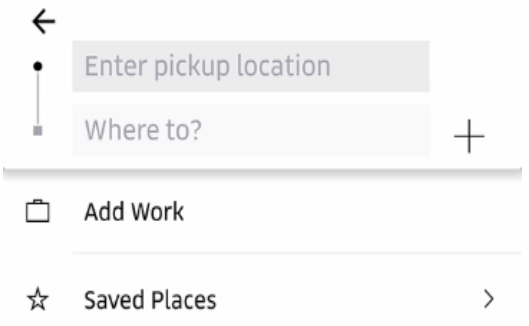

Figure 6: request page in Uber app

\subsubsection{Technical overview of Uber}

Uber's core activities lie in locations. For uber to function it must determine the locations of both its drivers and its riders. To accomplish this, Uber employs various technologies such as geofencing, maps, distance matrix and geofire.

\subsection{The gap}

Senga offers the client a way to contact the company. However, the whole process is taken over by the company. Senga hides the process up to delivery from the cargo owner as such the cargo owner does not have information on the whereabouts of his cargo until the goods are delivered. Uber on the other hand handles taxi services only.

For the problems at hand to be solved the two must be combined. The gap exists in combining the rider-centric approach in Uber with the truck services in Senga. This combination will form a consumer centric truck service system.

\section{METHODS}

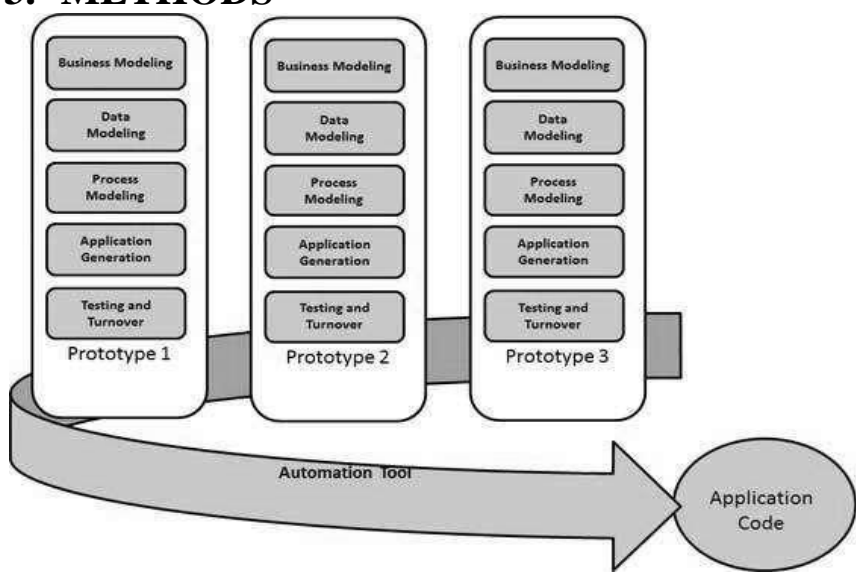

Fig 7 The Rapid Application Development lifecycle.[10]

The research adopted Rapid Application Development (RAD) methodology. This is a methodology that favors rapid generation of prototypes with minimal planning [10]

Since the research used an object oriented approach for the system development characterized by incremental and iterative steps, the RAD methodology allowed for thorough testing and a better understanding of the requirements of the system. RAD also offered several short testing periods reducing the risk of undetected errors at the end of each iteration. It also allowed for incorporation of new features that emerged with each iteration in the development of the system.

The final system's functional requirements identified are: 
1. The system should allow the users to login using their emails and passwords after registration.

2. The system should allow the consumer to enter delivery details.

3. The system should calculate price for delivery and display it.

4. The system should allow users to approve the delivery details and price.

5. The system should identify drivers close to the consumer and notify them of the delivery order.

6. The system should allow only one driver to accept an order.

7. The system should continuously display the driver's location to the consumer.

Non-functional requirements identified include:

1. The system should have easy to use buttons with short finger travel distance.

2. The system should effectively handle any arising exceptions during usage without crashes.

3. The system should have a user support center for any arising issues or questions.

4. The system should enforce installation of security and maintenance updates.

\subsection{System framework}

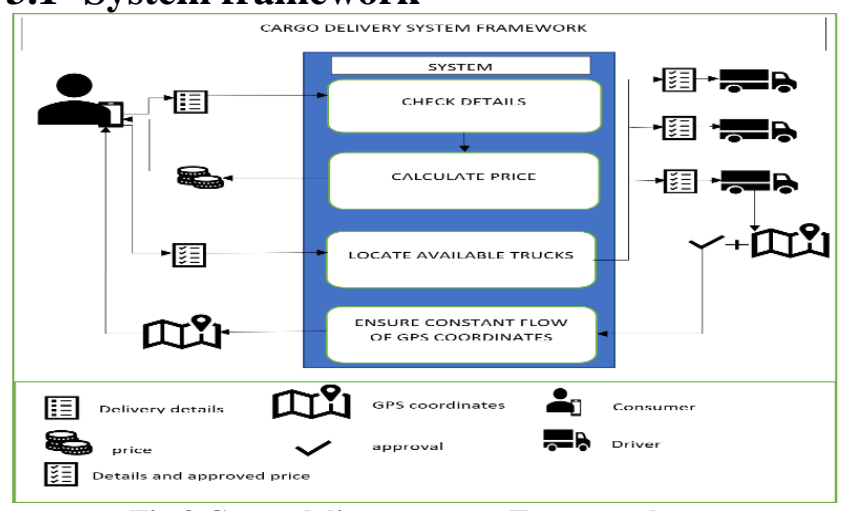

Fig 8 Cargo delivery system Framework

\section{RESULTS}

The implemented system was tested against its requirements using several tests. In each iteration of development unit tests were conducted to ensure that there were no errors in each individual module. For example, the details page was tested whether it had error checking mechanisms to ensure correct data entry. After unit test, integration testing was performed to check how the individual modules interacted with each other. Tests were done on the flow of data from one module to the other such as the flow of price from the price module to the order details page. The system then underwent system testing to ensure all requirements were met such as short finger travel distances, login authentications, and user support functions.

After the testing phase all requirements were met in both functional and non- functional requirements. The system showed effective recovery for all tested exceptions and all identified errors were removed. The system could still be brought down by unforeseen security vulnerabilities since no security tests were carried out. However, to prevent this all basic security precautions were carried out including ensuring that the user used a mixture of numbers, alphabets and special characters for the passwords.

\section{CONCLUSION}

The system that was developed as a result of this research is a good example of the use of mobile technology to reduce costs for businesses and increase coverage in the consumer market. The system is able to solve the problems identified which include theft and high transportation costs while increasing coverage to potential consumers through the use of technology. The system compensates fully for all just in time procurement system requirements.

To take full advantage of the mobile platform, the system should implement a delivery note generation page, offline access to history and an online or mobile payment module. Offline access will allow the consumers to save resources when checking their delivery history. The delivery note generation module will allow for customizing of the delivery note for organizations and automated filling in of the required data. A payments module will allow for other modes of payment apart from cash.

\section{REFERENCES}

[1] emarketer. (2017, July 18). Worldwide Retail and Ecommerce Sales: eMarketer's Estimates for 2016-2021. Retrieved from eMarketer: https://www.emarketer.com/Report/Worldwide-RetailEcommerce-Sales-eMarketers-Estimates20162021/2002090

[2] google. (2017, august 14). google APIs for android. Retrieved from geofence: https://developers.google.com/android/reference/com/go ogle/android/gms/maps/package-summary

[3] google. (2017, August 29). google maps APIs. Retrieved from Developers Guide: https://developers.google.com/maps/documentation/dista nce-matrix/intro

[4] google. (2018, January). consumer barameter with google. Retrieved from consumer barameter: https://www.consumerbarometer.com/en/trending/?count ryCode=KE\&category $=$ TRN-NOFILTER-ALL

[5] Railway gazette. (2017, May). Mombasa-Nairobi standard gauge railway opened. Retrieved from Railway gazette:

http://www.railwaygazette.com/news/infrastructure/singl e-view/view/mombasa-nairobi-standard-gauge-railwayopened.html

[6] Roy, J. (2001). Recent Trends In Logistics and the need for Real-Time Decision Tools In The Trucking Industry. 34th Hawaii International Conference on System Sciences (p. 1). Maui: IEEE.

[7] Senga. (2016). for shippers. Retrieved from senga: http://www.senga.co

[8] Statista. (2016, july). Number of smartphone users worldwide from 2014 to 2020 (in billions). Retrieved from Statista: https://www.statista.com/statistics/330695/number-ofsmartphone-users-worldwide/

[9] Transport World Africa. (2012, August 13). High transport costs, cargo theft -East Africa heads for ruins. Retrieved from Transport World Africa: 
International Journal of Computer Applications (0975 - 8887)

Volume 180-No.33, April 2018

http://www.transportworldafrica.co.za/2012/08/13/hightransport-costs-cargo-theft-east-africa-heads-for-ruins/

[10] tutorials point. (2017). SDLC-RAD Model. Retrieved from tutorialspoint simple easy learning: https://www.tutorialspoint.com/sdlc/sdlc_rad_model.htm
[11] uber. (2017). uber. Retrieved from How Uber works: https://www.uber.com/en-KE/ride/how-uber-works/

[12] Wenger, J. (2014, june 23). firebase. Retrieved from geofire

2.0 